\title{
Promoting sustainable energy in the New Zealand transport system: policies, programmes and strategic directions
}

\author{
D. J. Baars \\ Energy Efficiency and Conservation Authority of New Zealand
}

\begin{abstract}
This paper discusses the promotion of energy efficiency and renewable energy in the New Zealand transport system. It begins by examining the characteristics of New Zealand's transport system that influence energy use, including the age of vehicles, vehicle ownership rates and the total amount of vehicle kilometres travelled. The paper then overviews the range of targets, policies and programmes that are being used to promote greater energy efficiency and renewable energy in the New Zealand transport system, in order to reduce carbon emissions and enhance energy security. Two key measures are focused upon: a vehicle fuel economy labelling scheme and a vehicle fleet fuel economy target. The paper concludes by discussing the prospects for adopting electric vehicles in New Zealand, as a strategic step the country could take to further reduce and diversify its future transport energy use.
\end{abstract}

Keywords: energy efficiency, renewable energy, fuel economy, electric vehicles.

\section{Introduction}

This paper discusses New Zealand's targets, policies and programmes for the promotion of greater energy efficiency and renewable energy in the country's transport system. The paper also considers New Zealand's future prospects for adopting electric vehicles.

By international comparison, New Zealand's transport system is less energy efficient and lags behind other developed countries in the use of renewable energy, EECA [1].

The New Zealand Government is seeking to address this deficiency by pursuing various targets, policies and programmes with the aim of enhancing the 
sustainable energy profile of the country's transport system. These measures are also being pursued to reduce carbon emissions and improve energy security.

The sustainable transport energy measures described in this paper where either proposed or announced in the public domain by the New Zealand Government at the time of submitting this paper to conference (11 February 2009). Such measures can change with shifts in Government policy and readers should consult other information sources before using or quoting the content of this paper.

\section{Transport energy use in New Zealand}

Transport is the largest energy using sector of New Zealand's economy. In 2006 the sector accounted for 213 petajoules or $42 \%$ of the country's total energy use. The sector is also fossil fuel intensive and 2006 it consumed $85 \%$ of the total oil used in New Zealand. Of the total oil used in New Zealand in 2006, over 90\% was imported from foreign markets, EECA [2]. New Zealand's increasing historic dependency on imported oil is shown in Figure 1.

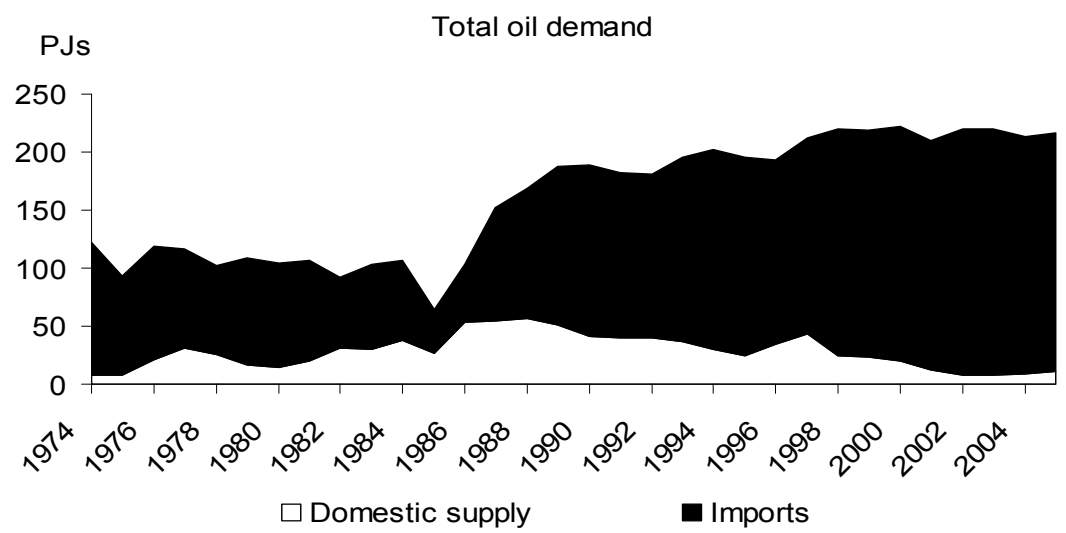

Figure 1: New Zealand's oil imports in petajoules (PJs), MED [3].

New Zealand's transport energy use has also been increasingly rapidly. Between 2001 and 2006 New Zealand's transport energy use increased by $14.6 \%$, or on average at $2.4 \%$ per annum, EECA [2].

Road transport remains the dominant mode in terms of energy use in the New Zealand transport system. In 2006 road transport accounted for $93.5 \%$ of the country's total transport energy consumed, EECA [2].

\subsection{Factors influencing New Zealand's vehicle fleet energy use}

As noted above, a large proportion of transport energy is used in road transport in New Zealand. Various characteristics of the country's light vehicle fleet determine its relatively poor energy use performance and the consequent high 
proportion of transport energy used in passenger road transport. Firstly, an increasing proportion of "used" imported light vehicles since the year 2000 has shifted the average age of the light vehicle fleet from 11.5 years in 2000 to 12.5 years in 2006, MoT [4]. New Zealand's fleet is therefore progressively aging and it lags behind other developed countries in terms of its energy use performance, EECA [1].

Another significant determinant of total vehicle fleet energy use is the amount of vehicle kilometres travelled (VKT). Recently total VKT in New Zealand has been increasing (see Figure 2), MoT [4].

Vehicle ownership rates have also been increasing and New Zealand now has one of higher rates amongst developed countries (see Figure 3), MoT [4]. This is

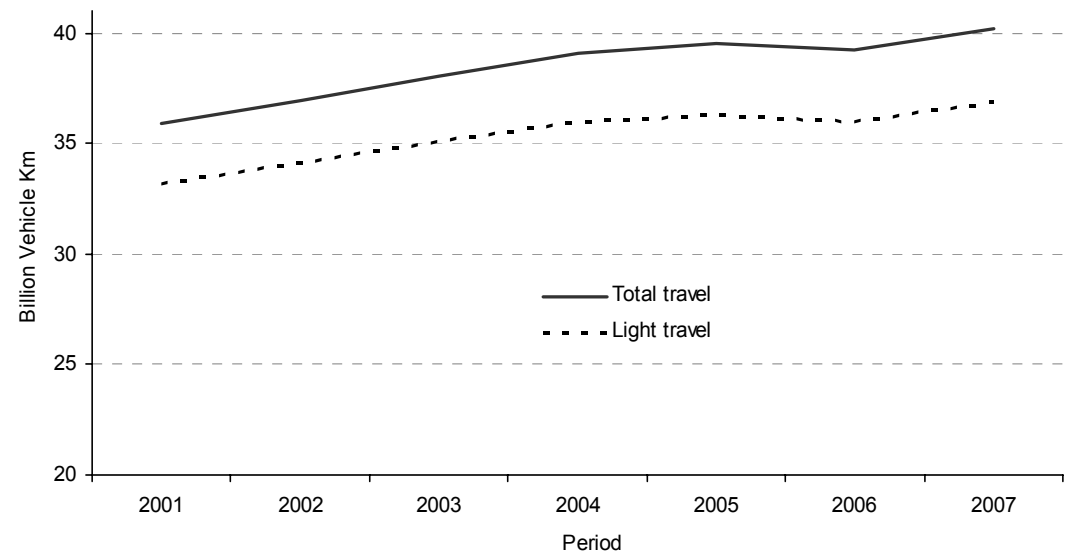

Figure 2: $\quad$ Increasing VKT in New Zealand (in billions of kilometres), MoT [4].

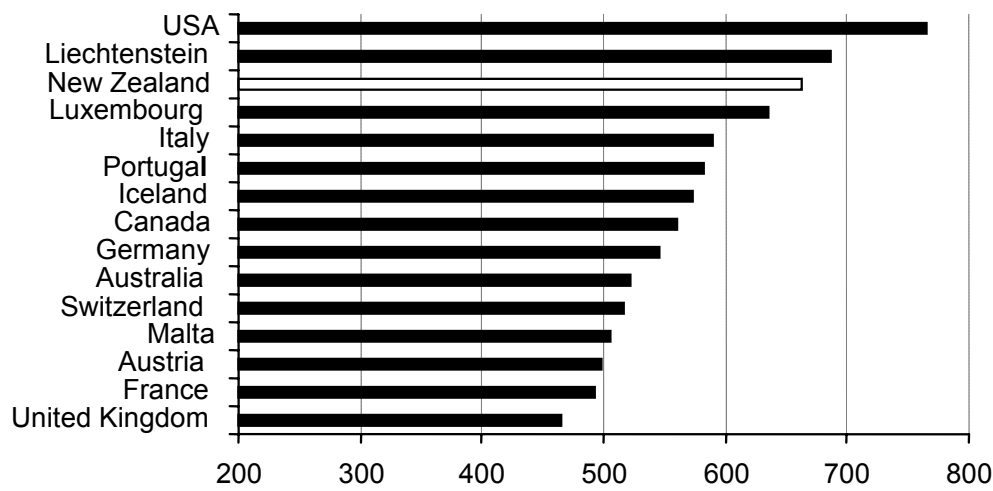

Figure 3: Vehicles per 1000 people by country, UNECE [5]. 
also considered to be a key determinant of New Zealand's vehicle fleet energy use, EECA [1].

Decreasing vehicle occupancy rates are another factor influencing the energy use of the New Zealand light vehicle fleet and since 2001 there has been a notable decline in these rates. A growth in vehicle ownership appears to have diminished vehicle occupancy rates in New Zealand, EECA [2].

The costs of owning and driving a vehicle (fuel and registration costs) in New Zealand are also relatively low by international comparison and this contributes to high rates of vehicle ownership and high vehicle kilometres travelled, which further influence transport energy use, EECA [1].

\section{Targets, policies and programmes}

A range of targets, policies and programmes are currently being progressed to enhance the energy efficiency and renewable energy use of New Zealand's transport system. These are stated in the New Zealand Energy Efficiency and Conservation Strategy (NZEECS), New Zealand Government [6].

The NZEECS is the "action plan" for energy efficiency and renewable energy in New Zealand. The Strategy states the following energy objective for the transport sector: "to reduce the overall energy use and greenhouse gas emissions from New Zealand's transport system”, New Zealand Government [6].

A number of transport energy targets are stated in the NZEECS to focus the sector's efforts in increasing energy efficiency and renewable energy use. The most significant of these is to "reduce the rated $\mathrm{CO}_{2}$ emissions per kilometre of new and used vehicles entering the fleet to a combined average of 170 grams $\mathrm{CO}_{2}$ per kilometre by 2015" (the present average is 215 grams $\mathrm{CO}_{2}$ per kilometre), New Zealand Government [6].

The sustainable transport energy policies and programmes currently being progressed in New Zealand fall into four broad categories: travel demand management, more efficient transport modes, improving the efficiency of vehicles and adopting renewable transport fuels. The key programmes and actions in each of these categories are discussed below.

\subsection{Travel demand management}

Travel demand management (TDM) is one approach being used to reduce New Zealand's transport energy use. For example, travel behaviour change (a subset of TDM) programmes are being implemented to encourage greater use of walking and cycling as an alternative to vehicle use. These programmes include the provision of advice, information and financial assistance to schools, businesses and public sector organisations to facilitate the development and implementation of "travel plans", NZTA [7].

Emphasis is also being placed upon improving walking and cycling infrastructure in urban and some rural areas. Various studies have also been undertaken into the impacts of introducing road pricing (including the energy benefits), MoT [8]. 
Funding of local public transport (buses, trains and ferries) by government has also increased in recent years and there has been more development of dedicated public transport infrastructure in many cities in New Zealand, including bus priority lanes, "park and ride" facilities and refurbished public transport terminals. "Teleworking" practices are also being encouraged by some regional governments and there is now a wider adoption of video conferencing technology by businesses as a substitute for travel (particularly air travel), EECA [2].

A significant project is also being led by central government to improve urban design. This will see planners developing cities with a more compact urban form that reduces the need to travel and related energy use.

\subsection{More energy efficient transport modes}

Related to travel demand management approaches, policies and programmes are also being pursued in New Zealand to encourage the use of more energy efficient transport modes. For example, regional public transport use targets (for buses, trains and ferries) have been developed by local transport control agencies, ARC [9], CRC [10].

The New Zealand Government has recently re-nationalised the rail system and is seeking to invest in the upgrade and extension of the track system and the purchase of new rolling stock for passenger and freight movement.

In order to facilitate greater freight movement by coastal shipping (and its connectivity with rail) more planning and investment is being also placed into port infrastructure.

\subsection{Vehicle fleet energy efficiency}

A major work stream is concerned with improving the energy efficiency of the New Zealand vehicle fleet. A number of programmes seek to intervene at strategic points in the energy using life cycle of New Zealand's vehicles to maximise their efficiency.

As discussed later in this paper, a vehicle fuel economy labelling scheme has already been implemented and a vehicle fuel economy target has been determined for New Zealand. These interventions are complimented by consumer information campaigns concerned with more fuel efficient driving behaviour and vehicle maintenance practices, NZTA [11].

Local authorities in two regions in New Zealand are trialling a vehicle scrappage scheme where a small bounty is being offered to motorists in order to retire old and poorly performing vehicles from the road, MOT [12]. To enhance the fuel efficiency of road freight movement a Government sponsored heavy vehicle driver training programme is also being developed.

\subsection{Renewable transport fuels}

An important step in reducing New Zealand's reliance on imported oil and reducing transport carbon emissions will be to produce greater volumes of renewable fuels domestically. 
There is considerable potential to do this through developing the supply of domestic biofuels and promoting the uptake of electric vehicles, EECA [1]. The possibility of electric vehicles is discussed in a later section of this paper.

The future possibility of hydrogen fuel cell vehicles is also acknowledged and being a "technology taker" (with no vehicle manufacturing industry) New Zealand is maintaining a "watching brief" on how this technology develops internationally.

\section{Key interventions}

In the author's view there are two key interventions that are being progressed that will have the greatest impact on improving New Zealand's transport energy efficiency and renewable energy use: a vehicle fuel economy labelling scheme and a vehicle fuel economy target. These are discussed below.

\subsection{Vehicle fuel economy labelling scheme}

A vehicle fuel economy labelling scheme now applies to new and used light vehicles (less than 3.5 tonnes) sold in New Zealand. The labels provide comparative fuel economy information to consumers to enable them to make more informed vehicle purchase decisions from a fuel economy perspective, EECA [13].

The scheme seeks to address an "information failure" with respect to the lack of availability of fuel economy information at the time of vehicle purchase. The application of the labelling scheme to imported "used" vehicles is a world first.

The information displayed on the label includes the estimated annual cost of running the vehicle per year (fuel costs), a comparative fuel economy rating on a

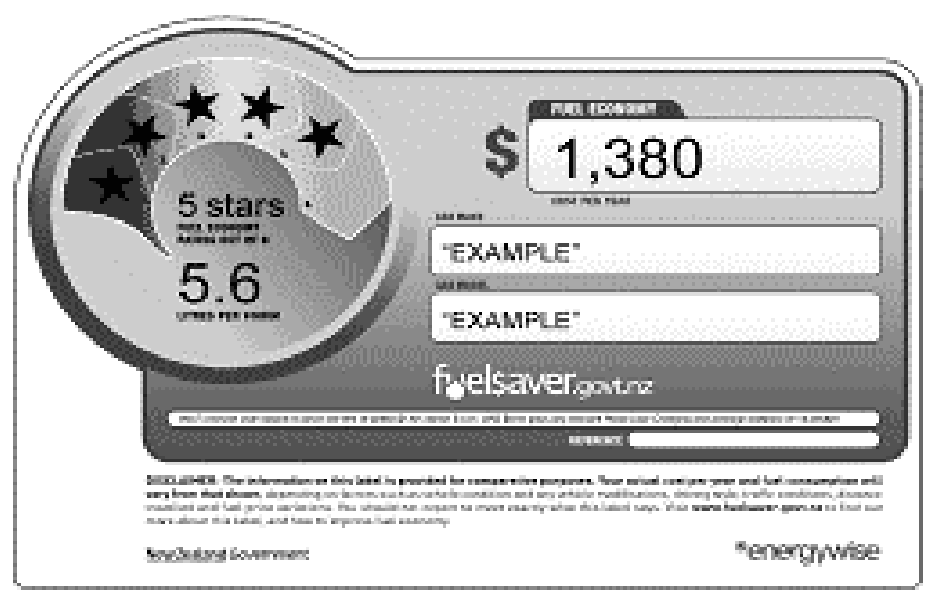

Figure 4: New Zealand vehicle fuel economy label, EECA [13]. 
six point scale (shown graphically in stars), and the tested fuel economy of the fuel in litres per $100 \mathrm{~km}$ (where available), EECA [13]. The fuel economy label used is shown in Figure 4.

The label must be displayed with the vehicle at point of sale or placed on a relevant website if the vehicle is sold over the internet. A website also provides fuel economy information for those selling vehicles and other information on improving the fuel economy of vehicles, such as fuel efficient driving and vehicle maintenance practices, NZTA [11].

Vehicles entering New Zealand are tested to either European or Japanese (typically "used" cars) test methods. The test results are reconciled using an algorhythm to provide a simple comparative start rating on the six point scale where one star or less represents the least fuel efficient vehicle available on the market, EECA [13].

The fuel economy labelling scheme is forecast to save approximately 1 mega tonne of $\mathrm{CO}_{2}$ emissions by 2033 and will result in 330 million New Zealand dollars of consumer fuel savings by that date, EECA [13].

The labelling scheme also forms a necessary prerequisite for the implementation of measures to give effect to a fuel economy target for vehicles entering the New Zealand fleet, as discussed below.

\subsection{Vehicle fleet fuel economy target}

A target to reduce the carbon emissions intensity of the New Zealand light vehicle fleet to 170 grams per kilometre of $\mathrm{CO}_{2}$ from the present based of around 215 grams has been stated by the New Zealand Government.

Achieving this target would save 175 petajoules of transport energy by 2025 and would result in a $\mathrm{CO}_{2}$ emissions reduction of 11.8 mega tonnes by that date. There would also be significant other co-benefits, including improved local air quality and fuel cost savings for consumers, MoT [14].

Various policy options are currently being considered by the New Zealand Government to achieve this target, including the possible use of a vehicle fuel economy standard, MoT [14]. This would effectively regulate the fuel efficiency of vehicles entering New Zealand from manufacturing countries. Presently New Zealand has no such border controls.

One of the policy options that could work in tandem with a fuel economy standard in New Zealand is a tradable credits approach. Such credits would represent exchangeable units of fuel economy potential, as opposed to carbon emission units.

The tradable credits approach to fuel economy standard would mean that any manufacturer improving the fuel economy performance of their vehicles at a rate greater than the standard annually requires would be able to sell those credits to other players in the industry.

This ability to trade credits would likely not only reduce compliance costs for manufacturers, but also introduces an incentive for potentially more dynamic energy efficiency improvements within the vehicle industry (at a rate greater than is required by the standard), MoT [14]. 


\section{Transitioning to electric vehicles in New Zealand}

In the author's view, a significant strategic opportunity for New Zealand to further reduce carbon emissions and improve national energy security would be to transition to electric vehicles.

In order for there to be a substantial reduction in carbon emissions from the land transport system, the predominant fuel source for electric vehicles should ideally be renewable electricity. However, even electric vehicles using electricity from thermal generation are still far more energy efficient than those using the internal combustion engine and electric vehicle uptake could still be pursued without additional renewable electricity generation.

There are some barriers to electric vehicles in New Zealand that will need to be overcome. These include the further development of the transmission infrastructure required to accommodate the extra electricity demand and the installation of time of use metering (or "smart metering" technology) in households and businesses to effectively manage the electricity demand for the charging of electric vehicles (the larger part of which would likely occur at night).

Improvements in the battery technology of electric vehicles to provide the driving range necessary for New Zealand settlements patterns will also be required.

The limitations presently placed by transmission infrastructure and driving range mean that electric vehicles may initially be a niche application for urban areas, rather than an inter-city transport option in New Zealand. A transition to hybrid electric and plug-in hybrid vehicles may also be a stepping stone to full electric transport at a later date.

Electric vehicles could also be deployed in distributed renewable electricity generation projects in New Zealand (using "vehicle-to-grid" approaches) to enable the development of a more de-centralised and resilient electricity generation system that affords greater regional level energy security, EC [15].

\section{Conclusions}

New Zealand is currently pursuing targets, policies and programmes to improve the energy efficiency and renewable energy use of the country's transport system, in order to reduce carbon emissions and enhance energy security.

There is potential for considerable improvement, particularly concerning the energy efficiency of the country's light vehicle fleet that accounts for approximately $90 \%$ of the total transport energy used in New Zealand.

Realising that there is no one "silver bullet" solution to reducing transport energy use and that it represents a systemic issue, policy makers are using a range of measures in New Zealand to address transport energy use. These include measures across the four key means of travel demand management, increasing vehicle fleet energy efficiency, using more efficient modes and adopting renewable transport fuels. 
Amongst the mix of measures available the author considers that there are two key interventions focused on the light vehicle fleet that will have a greatest impact: a vehicle fuel economy scheme and a vehicle fleet fuel economy target.

Looking ahead strategically, the author considers that the best direction that New Zealand could take to further reduce transport energy use would be to transition quickly to electric vehicles.

This technology has the potential to more than halve New Zealand's transport energy use and emissions by 2040 . However, it will ideally require a substantive increase in renewable electricity generation, improvements in battery technology, increased electricity transmission capacity and the use of "smart metering" technology at the point of vehicle charging.

\section{References}

[1] Situation Assessment Report: Review of the National Energy Efficiency and Conservation Strategy. New Zealand Energy Efficiency and Conservation Authority (EECA), Wellington, New Zealand, 2006.

[2] Year 5 Monitoring Report. New Zealand Energy Efficiency and Conservation Authority (EECA), Wellington, New Zealand. In progress.

[3] New Zealand Energy Use Data File. New Zealand Ministry of Economic Development (MED), Wellington, New Zealand. http://med.govt.nz/

[4] New Zealand Vehicle Fleet Statistics. New Zealand Ministry of Transport (MoT), Wellington, New Zealand. http://www.transport.govt.nz/assets /Images/NewFolder-2/The-NZ-Vehicle-Fleet-v13FINAL.pdf

[5] Transport Statistics. United Nations Economic Commission for Europe (UNECE), Geneva, Switzerland. http://www.unece.org/stats/trends2006 /transport.htm

[6] New Zealand Energy Efficiency and Conservation Strategy. New Zealand Government, Wellington. http://www.eeca.govt.nz/eeca-library/eecareports/neecs/report/nzeecs-07.pdf

[7] NZTA http://www.landtransport.govt.nz/sustainable-transport/travelbehaviour-change/

[8] MoT http://www.transport.govt.nz/arpes-index/

[9] ARC http://www.arc.govt.nz/transport/

[10] CRC http://www.ecan.govt.nz/Plans+and+Reports/transport/

[11] NZTA http://www.fuelsaver.govt.nz/

[12] Trial Vehicle Scrappage Report. New Zealand Ministry of Transport (MoT), Wellington. New Zealand. http:/www.transport.govt.nz/vehiclescrappage-report-1/

[13] EECA http://www.eeca.govt.nz/transport/vehicle-fuel-economy/index.htm

[14] Improving the Fuel Economy of Vehicles Entering New Zealand: A Discussion Paper for Public Comment. New Zealand Ministry of Transport (MoT), Wellington, New Zealand. http://www.transport.govt.nz/assets/ NewPDFs/Improving-Fuel-Economy-Paper.pdf

[15] EC http://www.electricitycommission.govt.nz/opdev/modelling/ 